Indian J. Anim. Hlth. (2020), 59(1) : 01-10

DOI: 10.36062/ijah.59.1.2020.01-10

\title{
COVID-19: PANIC VIS-A-VIS PANDEMIC
}

\author{
R. BISWAS ${ }^{* 1}$, C. DEBNATH ${ }^{1}$, I. SAMANTA², R. BARUA ${ }^{1}$ AND A. D. SINGH ${ }^{1}$
}

${ }^{1}$ Department of Veterinary Public Health, West Bengal University of Animal and Fishery Sciences, 37, K. B. Sarani, Kolkata-700 037, West Bengal, India

${ }^{2}$ Department of Veterinary Microbiology, West Bengal University of Animal and Fishery Sciences, 37, K. B. Sarani, Kolkata-700 037, West Bengal, India

The pandemic of COVID-19 was caused by the novel severe acute respiratory syndrome coronavirus 2 (SARS-CoV-2) showed an exceptional challenge to the human population over the globe. The purpose of this review is mainly to review the organism, clinical characteristics, diagnosis, and treatment of COVID-19 and also to remark concisely on the epidemiology and pathology based on the present experience in the world as well as Indian perspective. We focused in this review on the origin, epidemiology, clinical symptoms and preventive measures of the disease. This review has compiled the updated information about COVID-19 with the hope that it will be helpful to the public health professionals in their knowledge.

Key words: COVID-19, India, Public health, SARS-CoV-2

\section{Introduction}

The relatively short history of the coronaviruses (CoVs) began in the early 1930s when an acute respiratory infection of domesticated chickens was shown to be caused by a virus now known as avian infectious bronchitis virus (IBV). The term coronavirus was adopted for this agent and other similar agents in 1968, and in 1975 the name Coronaviridae was accepted for the family. Coronaviruses are pleomorphic, enveloped, positive sense and single-stranded RNA viruses with a nucleocapsid of helical symmetry, ranging from $80 \mathrm{~nm}$ to $160 \mathrm{~nm}$ in diameter. The spike like projections on its surface giving it a crown like or fringed appearance, redolent of the solar corona under the electron microscope; hence the name coronavirus. These spikes are about $20 \mathrm{~nm}$ in length. This virus is widespread in nature; infects a range of hosts including man with variable tissue tropisms and are highly species specific (Richman et al., 2016).
Under the order Nidovirales, there are three families; Arteriviridae and the Roniviridae belonging pathogens are of birds and insects, respectively and the third one is Coronaviridae family, consist of two subfamilies, Coronavirinae and Torovirinae. Torovirinae containing viruses cause mainly enteric infections of horses, cattle, pigs, cats and goats. Subfamily Coronavirinae is subdivided into four genera Alphacoronavirus, Betacoronavirus, Gammacoronavirus and Deltacoronavirus. Members of the Coronaviridae are known to cause respiratory or intestinal infections in humans and other animals. Recombination rates of CoVs are very high because of continuous transcription errors and RNA Dependent RNA Polymerase (RdRp) jumps. Coronaviruses are zoonotic pathogens which produce diseases in humans and various animals with a wide range of clinical characteristics from asymptomatic progression to necessity of hospitalization in the 
intensive care unit; causing infections in respiratory, hepatic, gastrointestinal and neurologic systems (Drexler et al., 2010; Woo et al., 2010; Yin et al., 2018). The 2019 novel coronavirus (2019-nCoV), presently it is called severe acute respiratory syndrome corona virus 2 (SARS-CoV-2), is rapidly spreading from its origin in Wuhan City of Hubei Province of China to the rest of the world (Wang et al., 2020). On February 11, 2020 it was named SARS-Cov-2 and the disease caused by this virus was named 'Coronavirus Disease 2019' (abbreviated "COVID-19").

\section{Origin of new virus}

Like the other viruses (SARS-CoV and MERS), SARS-CoV-2 has many potential natural hosts or reservoirs, intermediate hosts and final hosts which attitudes great challenges for prevention and treatment of the disease. This virus belongs to Betacoronavirus, a large class of viruses which are very predominant in nature. Six coronaviruses were previously known to cause diseases in humans. NL63 \& 229E (Alphacoronavirus), OC43 \& HKU1 (Betacoronavirus) generally cause mild respiratory disease and SARS-CoV2 is the latest and seventh member of the coronavirus family that infects human beings after SARS-CoV in 2003 and MERS-CoV in 2012 (Zhu et al., 2020). In comparison with SARS-CoV and MERS-CoV, SARS-Cov-2 virus has high infectivity and transmission ability, despite of low mortality rate as the mortality rate of SARS-CoV and MERS-CoV was about $10 \%$ and 35\%, respectively (Donnelly et al., 2019; Liu et al., 2020). SARS-CoV and MERS-CoV are of zoonotic origins. In case of SARS-CoV outbreak in 2003, exotic mammals in wet markets, such as palm civets and raccoon dogs, were supposed to be the animal sources of the virus (Guan et al., 2003) while MERS-CoV was widely distributed in dromedary camels. In Middle East countries, more than $90 \%$ of dromedary camels were reported seropositive for MERS-CoV (Hemida et al., 2013; Reusken et al., 2013).

\section{Coronavirus diseases in animals}

There are several animal coronaviruses which have no zoonotic importance but having the veterinary significance. In case of pigs, pig respiratory coronavirus (PRCoV) develops respiratory infection, porcine transmissible gastroenteritis virus (TGEV) infects the epithelial cells of the intestine of piglets (Doyle and Hutchins, 1995) and porcine epidemic diarrhoea virus (PEDV) causes diarrhoea due to infection in intestine and colon. Interestingly, PEDV is genetically more closely related to human $\mathrm{CoV}$ 229E than to the other animal alphacoronaviruses (Saif, 2004). Bovine coronavirus (BCoV) is a universal worldwide virus which causes both respiratory and enteric diseases as winter dysentery in adult cattle and diarrhoea in calves. Canine coronaviruses $(\mathrm{CCoV})$ is largely prevalent in dog population and it causes enteric diseases in canine. Canine coronaviruses $(\mathrm{CCoV})$ type I and type II are included under alphacoronavirus and CCoV-type I is genetically more similar to feline corona virus type I (FCoV type I) than to CCoV type II (Pratelli et al., 2003). Two types of FCoVs have been documented which include feline infectious peritonitis virus (FIPV) and feline enteric coronavirus (FECoV). In poultry, Infectious bronchitis virus (IBV) causes a highly contagious disease which is spread by aerosol thus this this plays a very important role in poultry industry in relation with economy. Different commercial vaccines are available against $\mathrm{CCoV}$, FCoV and IBV.

\section{Zoonotic connection}

A direct or indirect contact must occur for the disease to emerge and spread in human. Natural synanthropic association and the multifarious relation of biology, ecology, behavior, landscape evolution, and anthropization are responsible to transmit the disease from animal to human. Bat viruses have been associated with human, livestock and wild animal diseases. The sudden occurrence of newly recognized viruses causing fatal diseases and has been shocking to the scientific and medical societies (Moratelli and 
Calisher, 2015). Bats are recognized as important reservoir host of zoonotic viruses (Luis et al., 2013). The large population size of bats, hunting the bats as food animal, consumption of bush meat, agricultural and livestock practices, and penetration of bat habitat by humans will likely lead to continued spillover events and outbreaks of different emerging and re-emerging diseases (Wood et al., 2012).

\section{A novel disease}

In December 2019, in Wuhan, capital of Hubei province and a chief transportation hub of China, adults humans were started presenting cases to the local hospitals with severe pneumonia of unknown source. Many of those preliminary cases had a common exposure to the Huanan wholesale seafood market which was also used to trade live wild animals. The monitoring and surveillance system were augmented remembering the previous outbreak experience of SARS-CoV and respiratory samples of patients were sent to the reference laboratories for etiologic investigations. On $31^{\text {st }}$ December, 2019, China notified the outbreak report to the World Health Organization and on $1^{\text {st }}$ January, the Huanan sea food market was closed (Sanower et al., 2020). The first unknown pneumonia case was detected on December 12, 2019, and possible influenza and other coronaviruses were ruled out by laboratory testing (Sahin et al., 2020). On $22^{\text {nd }}$ January, 2020, novel $\mathrm{CoV}$ was declared to be originated from wild bats and fixed under Group 2 of betacoronavirus which contains Severe Acute Respiratory Syndrome Associated Coronavirus (SARS-CoV). With the similarity of SARS-CoV2 to bat SARS-CoV-like coronaviruses, it is expected that bats assist as reservoir hosts for its progenitor while pangolins and snakes are thought to be the intermediate hosts ( $\mathrm{Li}$ et al., 2020). Although, sample from a Rhinolophus affinis bat (RaTG13) is found to be approximately $96 \%$ identical overall to SARS-CoV-2 and its spike diverges in the receptor binding domain, which suggests that it may not bind efficiently to human ACE2 (Angiotensin converting enzyme 2) (Wan et al., 2020). Malayan pangolins (Manis javanica) were unlawfully imported into Guangdong province containing coronaviruses similar to SARS-CoV-2 (Zhang et al., 2020). Although the RaTG13 bat virus showed closest relationship to SARS-CoV-2 through the genome and some pangolin coronaviruses exhibited strong resemblance to SARS-CoV-2 in the RBD (receptor binding domain), including all six key RBD residues. It spreads by human-to-human transmission via droplets or direct contact, and infection has been estimated to have an average incubation period of 6.4 days (Lai et al., 2020). Interestingly, for high resemblance of receptor-binding domain (RBD) in Spike-protein, several analyses reveal that SARS-CoV-2 uses angiotensin-converting enzyme 2 (ACE2) as receptor, just like as SARS-CoV (Hoffmann et al., 2020). This clearly suggests that the spike protein of SARS-CoV-2 was optimized for binding to human-like ACE2 and it was occurred as a result of natural selection (Kristian et al., 2020). Although the zoonotic source of SARS-CoV-2 is yet to confirm but its genome sequence has exhibited close identity (88\%) with two batderived SARS-like coronaviruses (bat-SLCoVZC45 and bat-SL-CoVZXC21). SARS-CoV2 was genetically distinct from SARS-CoV and MERS-CoV as it was revealed by phylogenetic analysis (Khan et al., 2020). Peking university study suggests that SARS-CoV-2 infection is probably caused by snakes (Ji et al., 2020) but later it was reported that snakes are not the hosts of SARS-CoV-2 (Zhang et al., 2020). Wuhan institute of virology reported that the resemblance of gene sequence between SARS-CoV-2 and bat coronavirus was as high as $96.2 \%$ (Zhou et al., 2020). The resemblance between SARS-CoV-2, isolated from pangolin and the virus strains currently infecting humans is as high as $99 \%$, which has been reported by using macrogenomic sequencing (Xu et al., 2020). Although the outcomes of current research have not yet completely elucidated the potential natural host and the intermediate host of the SARS-CoV-2, adequate suggestions have demonstrated that this virus might be sourced from wild animals ( $\mathrm{Li}$ et al., 2020). 


\section{Epidemiology}

The causative agent was identified as a novel coronavirus (2019-nCoV), followed by gene sequence analysis and the development of detection methods on $7^{\text {th }}$ January 2020 from sea food market in Wuhan city (Wang et al., 2020). The most celebratory time of the year in China is Chinese Lunar New Year holiday, was coincided with the emergence of COVID-19, during which a massive human migration took place as individuals travelled back to their hometowns. With the previous experience of SARS-CoV, social distancing has been effective in epidemics which decrease human-to-human transmission and reducing morbidity and mortality (Ferguson et al., 2005). Like the SARS outbreak, this outbreak occurred during the spring festival in China, which is the most famous traditional festival in China, where nearly 3 billion people travel countrywide. These conditions instigated favorable conditions for the transmission of this highly transmissible disease and severe difficulties to prevent and control of the outbreak. The duration of the Spring Festival of China was between $17^{\text {th }}$ January and $23^{\text {rd }}$ February in 2003, when the SARS epidemic peaked, while the period of the present year festival was between $10^{\text {th }}$ January and $18^{\text {th }}$ February in 2020. Probably this could be the reason that there was a rapid escalation of COVID-19 cases between $10^{\text {th }}$ to $22^{\text {nd }}$ January, 2020. The estimated number of travelers during the 2020 spring festival has ascended 1.7 times compared with the number of travelers in 2003 and reached to 3.11 billion from 1.82 billion. This large scale travel traffic has also created favorable situations for spreading of this disease which became difficult to control. On $11^{\text {th }}$ March, 2020, the World Health Organization (WHO) has declared the novel coronavirus (COVID-19) outbreak as a global pandemic. As on $15^{\text {th }}$ May, 2020, 213 countries and territories are affected and total 45,26,934 human SARSCoV-2 positive cases reported from the globe where number of fatalities crossed more than 3,03,307 and continuing (www.worldometers.info). USA leads in total confirmed cases as well as death report trailed by Spain and Russia (Table 1).

\section{Indian perspective}

On $30^{\text {th }}$ January, India reported its first case of COVID-19 in Kerala, which increased to three cases by $3^{\text {rd }}$ February, 2020 and all were students who had returned from Wuhan, China. As on $15^{\text {th }}$ May, 2020, the Ministry of Health and Family Welfare have confirmed a total of 81,970 cases, 27,920 recoveries (including 1 migration) and 2649 deaths in the country. As on $15^{\text {th }}$ May, 2020, Maharashtra confirmed 25,922 cases that

Table 1. Top trending countries, reported maximum number COVID-19 cases as on $15^{\text {th }}$ May 2020

\begin{tabular}{lccc}
\hline Country & $\begin{array}{c}\text { Total } \\
\text { cases }\end{array}$ & $\begin{array}{c}\text { Total } \\
\text { deaths }\end{array}$ & $\begin{array}{c}\text { Total } \\
\text { recovered }\end{array}$ \\
\hline USA & $1,457,593$ & 86,912 & 318,027 \\
Spain & 272,646 & 27,321 & 186,480 \\
Russia & 252,245 & 2,305 & 53,530 \\
UK & 233,151 & 33,614 & N/A \\
Italy & 223,096 & 31,368 & 115,288 \\
Brazil & 203,165 & 13,999 & 79,479 \\
France & 178,870 & 27,425 & 59,605 \\
Germany & 174,975 & 7,928 & 150,300 \\
Turkey & 144,749 & 4,007 & 104,030 \\
Iran & 114,533 & 6,854 & 90,539 \\
China & 82,933 & 4,633 & 78,209 \\
India & 82,052 & 2,649 & 27,969 \\
\hline
\end{tabular}


is highest in the country and Kerala combated the disease excellently though the state reported the first case from the country. On $22^{\text {nd }}$ March, 2020 , India observed a 14 hours voluntary public curfew. On 24 March, the prime minister ordered a countrywide lockdown for 21 days, across the entire 1.3 billion population of India and subsequent lockdown has been extended up to $3^{\text {rd }}$ May, 2020 and further up to $17^{\text {th }}$ May, 2020, thereafter $4^{\text {th }}$ phase lockdown was declared till $31^{\text {st }}$ may, 2020. On $14^{\text {th }}$ March, the Government of India declared the pandemic as a "notified disaster" under the Disaster Management Act, 2005, permitting the states to spend a larger part of funds from the state disaster response fund to fight against the disease. In India, the diagnostic procedure is going on across the country in more than 100 (National Accreditation Board for testing and calibration laboratories) NABL accredits virology laboratories.

\section{Climatic correlation}

Although cases of COVID-19 are reported all over the world, most outbreaks exhibit a pattern of clustering in relatively cool and dry areas (www.medrxiv.org). SARS-CoV-2 has established substantial community spread in cities and districts along a narrow east west distribution roughly along the $30-50^{\circ} \mathrm{N}^{\prime}$ corridor at constantly similar weather patterns consisting of average temperatures of $5-11^{\circ} \mathrm{C}$, combined with low specific (3-6 g/kg) and absolute humidity (4-7 g/ $\left.\mathrm{m}^{3}\right)$. Through $10^{\text {th }}$ March, 2020, significant community transmission has been occurred in a constant east and west pattern. Initially, the new epicenters of disease were all unevenly along the $30-50^{\circ} \mathrm{N}^{\prime}$ zone; to South Korea, Japan, Iran and Northern Italy. COVID-19 failed to transmit expressively to countries closely north (such as Russia and Mongolia) and south of China. The number of patients and reported deaths in South East Asia is much fewer when compared to more temperate areas as mentioned above. The connotation between temperature and humidity in the area affected with COVID-19 needs special strategies (Sanower et al., 2020).

\section{SARS-CoV-2 in Animal}

On $27^{\text {th }}$ February, 2020, Hong Kong's Agriculture, Fisheries, and Conservation Department (AFCD) reported that samples collected from the nasal and oral cavities of a quarantined 17 years old Pomeranian whose owner was detected COVID19, had found "weak positive" for SARS-CoV-2, by using a real time RT-PCR (reverse transcriptionpolymerase chain reaction) test. The Federal Agency for the Safety of the Food Chain (FASFC) in Belgium reported on $18^{\text {th }}$ March 2020, that the Faculty of Veterinary Medicine at the University of Liege, could detect viral RNA of SARS-CoV-2 by real time RT-PCR from the faeces and vomit of a cat with digestive and respiratory clinical signs (www.avma.org). According to the Scientific Committee of the FASFC, it was not known whether the sequences of virus found in the cat and the owner were similar, although the cat owner was infected with SARS-CoV-2. On 30 ${ }^{\text {th }}$ March, 2020, the AFCD reported that a pet cat, lived in a residence with an individual was confirmed COVID-19 by using real time RT-PCR for SARS-CoV-2 from oral, nasal, and rectal samples (www.avma.org). On $5^{\text {th }}$ April, 2020, the National Veterinary Services Laboratories of United States Department of Agriculture (USDA) confirmed SARS-CoV-2 in one tiger in a zoo in New York. This is the first case of tiger which was infected with COVID-19 (www.aphis.usda.gov).

\section{Clinical classification}

COVID-19 reveals with a wide clinical characteristics, ranging from asymptomatic to septic shock and multi organ dysfunction. COVID-19 is classified on the basis of severity of the presentation. The disease can be categorized into mild, moderate, severe, and critical. The most common clinical symptoms of the patients show fever (98.6\%), fatigue (69.6\%), dry cough and diarrhea (Wang et al., 2020). Immunocompromised and aged patients are at the highest risk of fatality (Hassan et al., 2020). On the basis of severity, China CDC classified the clinical symptoms into-1)Mild disease: $81 \%$ of cases found under this class with 
mild pneumonia and non-pneumonia, 2) Severe disease: $14 \%$ of cases found with dyspnea, respiration rate $\geq 30 / \mathrm{min}$, blood oxygen saturation $\leq 93 \%, \mathrm{P} / \mathrm{F}$ ratio [the ratio between the blood pressure of the oxygen (partial pressure of oxygen, $\mathrm{PaO} 2$ ) and the percentage of oxygen supplied (fraction of inspired oxygen, FiO2)] < 300, and/or lung infiltrates $>50 \%$ within 24 to 48 hours and 3) Critical disease: respiratory failure, septic shock, and/or multiple organ dysfunction (MOD) or failure (MOF); this occurred in 5\% of cases (Wu and McGoogan, 2020). On $13^{\text {th }}$ March 2020, WHO published clinical syndromes associated with COVID-19 (Table 2).

Table 2. Clinical syndromes associated with COVID-19

\begin{tabular}{ll}
\hline \multicolumn{1}{c}{ Illness } & \multicolumn{1}{c}{ Symptoms } \\
\hline & Patients uncomplicated upper respiratory tract viral infection may have non- \\
& specific symptoms such as fever, fatigue, cough (with or without sputum \\
& production), anorexia, malaise, muscle pain, sore throat, dyspnea, nasal \\
& congestion, or headache. Rarely, patients may also present with diarrhoea, nausea, \\
& and vomiting (Chen et al., 2020; Guan et al., 2020). The elderly and \\
Mild illness & immunosuppressed may present with atypical symptoms. Symptoms due to \\
& physiologic adaptations of pregnancy or adverse pregnancy events, such as \\
& dyspnea, fever, GI-symptoms or fatigue, may overlap with COVID19 symptoms.
\end{tabular}

Onset: within 1 week of a known clinical insult or new or worsening respiratory symptoms. Chest imaging (radiograph, CT scan, or lung ultrasound): bilateral opacities, not fully explained by volume overload, lobar or lung collapse, or nodules. Origin of pulmonary infiltrates: respiratory failure not fully explained by cardiac failure or fluid overload. Need objective assessment (e.g. echocardiography) to exclude hydrostatic cause of infiltrates/oedema if no risk factor present. Oxygenation impairment in adults - Mild ARDS: $200 \mathrm{mmHg}<$ $\mathrm{PaO} 2 / \mathrm{FiO} 2 \mathrm{a} \leq 300 \mathrm{mmHg}$ (with PEEP or CPAP $\geq 5 \mathrm{cmH}_{2} \mathrm{O}$, or non-ventilated)

Acute respiratory distress syndrome (ARDS)

(Force et al., 2012; Khemani et al., 2015; Riviello et al., 2016)
- Moderate ARDS: $100 \mathrm{mmHg}<\mathrm{PaO} 2 / \mathrm{FiO} 2 \leq 200 \mathrm{mmHg}$ (with PEEP $\geq 5$ $\mathrm{cmH}_{2} \mathrm{O}$, or non-ventilated) - Severe ARDS: $\mathrm{PaO} 2 / \mathrm{FiO} 2 \leq 100 \mathrm{mmHg}$ (with PEEP $\geq 5 \mathrm{cmH}_{2} \mathrm{O}$, or non-ventilated) $\cdot$ When $\mathrm{PaO} 2$ is not available, $\mathrm{SpO} 2 / \mathrm{FiO} 2 \leq 315$ suggests ARDS (including in non-ventilated patients). Oxygenation impairment in children: note $\mathrm{OI}=$ Oxygenation Index and OSI = Oxygenation Index using $\mathrm{SpO} 2$. Use $\mathrm{PaO} 2$-based metric when available. If $\mathrm{PaO} 2$ not available, wean $\mathrm{FiO} 2$ to maintain $\mathrm{SpO} 2 \leq 97 \%$ to calculate $\mathrm{OSI}$ or $\mathrm{SpO} / \mathrm{FiO} 2$ ratio: $\bullet$ Bi level ( NIV or CPAP) $\geq 5 \mathrm{cmH}_{2} \mathrm{O}$ via full face mask: $\mathrm{PaO} 2 / \mathrm{FiO} 2 \leq 300 \mathrm{mmHg}$ or $\mathrm{SpO} 2 / \mathrm{FiO} 2 \leq 264 \bullet$ Mild ARDS (invasively ventilated): $4 \leq \mathrm{OI}<8$ or $5 \leq \mathrm{OSI}<$ $7.5 \cdot$ Moderate ARDS (invasively ventilated): $8 \leq$ OI $<16$ or $7.5 \leq$ OSI $<12.3$ Severe ARDS (invasively ventilated): $\mathrm{OI} \geq 16$ or $\mathrm{OSI} \geq 12.3$.

Adults: Life-threatening organ dysfunction caused by a dysregulated host response to suspected or proven infection. Signs of organ dysfunction include: altered mental status, difficult or fast breathing, low oxygen saturation, reduced urine output, fast heart rate, weak pulse, cold extremities or low blood pressure, skin mottling, or laboratory evidence of coagulopathy, thrombocytopenia, acidosis, high lactate, or hyperbilirubinemia.

Children: Suspected or proven infection and $\geq 2$ age- based systemic inflammatory response syndrome criteria, of which one must be abnormal temperature or white blood cell count. 


\section{Diagnostic protocol}

According to $\mathrm{WHO}$ guideline, laboratory diagnosis of COVID-19 is based on a positive RT-PCR test but the target gene for diagnosis may be different in different countries. The diagnostic tool is being used in India is RT-PCR with the guidelines of WHO and ICMR. Target genes are for screening and confirmatory assays by RT-PCR, e.g. ORF1ab and $\mathrm{N}$ in Chinese laboratory protocol, while (RNA dependent RNA polymerase) RdRp, $\mathrm{E}$ and $\mathrm{N}$ are checked in Germany. Furthermore, three targets in $\mathrm{N}$ gene are considered in the US protocol (WHO, 2020). Indian Council of Medical ResearchNational Institute of Virology (ICMR-NIV), Pune implemented a real-time RT-PCR assay for screening (E gene assay) and confirmation (RdRp, $\mathrm{N}$ and ORF gene) along with housekeeping Rnase $\mathrm{P}$ gene (Corman et al., 2020). On $4^{\text {th }}$ April, 2020, the Indian Council of Medical Research (ICMR) authorized the use of the Truenat beta CoV test in Truelab work station as a screening test for COVID19. For routine viral test, BSL-2 laboratory is recommended with all precautionary measures while for research work BSL-3 laboratory is necessary because of culture, propagation and neutralization examination.

\section{Treatment approach}

In general, there are little or no treatment options for viral diseases that occur unexpectedly (Sahin et al., 2020). Treatment is essentially supportive and symptomatic. There is no vaccine or effective treatment to prevent COVID-19 infection. The first step is to confirm satisfactory isolation of an individual to avoid transmission of the disease from infected persons, patients and healthcare workers. With the experience of SARS-CoV and MERS$\mathrm{CoV}$, patients treated with lopinavir/ ritonavir with ribavirin showed better result as compared to those given ribavirin alone (Chen et al., 2020). Remdesivir and chloroquine displayed as highly effective drug in vitro for the control of 2019nCoV infection (Wang M. et al., 2020). Treatment with only remdesivir or in combination with chloroquine or beta interferon was documented effective against COVID-19 infection. Till now this approach has not elicited any obvious adverse effects (Corman et al., 2020).

\section{Food safety and COVID-19}

Many countries are following the advice from the World Health Organization (WHO) concerning the introduction of physical distancing measures as one of the ways in which transmission of the disease can be reduced (WHO, 2020). The food industry should have Food Safety Management Systems (FSMS) based on the Hazard Analysis and Critical Control Point (HACCP) principles, to succeed food safety hazards and to prevent food contamination. Although, the genetic material (RNA) of SARS-CoV-2 has been isolated from stool samples of infected patients (Ong et al., 2020), but there is no report or any evidence of faecal-oral transmission. Hand-washing after using the toilet is always an important practice especially, when working with food, as it is recommended by World Health Organization. WHO also suggests for the food workers to attain training on COVID-19; normal routine health checkup and maintain the physical distancing (at least 1 metre) during working hour. Drivers and other staffs delivering food to premises should not leave their vehicles during delivery. In general, the infectivity of enveloped viruses like COVID19 virus is reduced by using $70-80 \%$ alcoholbased disinfectants (ethanol, propan-2-ol, propan1-ol). Quaternary ammonium compounds and chlorine also have virucidal properties which can be used as disinfectant.

\section{Preventive measures}

For the general population, the best preventive measure is to avoid being exposed to the virus. Infection preventive and control (IPC) measures that may decrease the chances of exposure by implementing the following measures; use of face masks; by covering coughs and sneezes with tissues and then safely disposed (or, if no tissues are available, use a flexed elbow to cover the cough or sneeze); frequent washing of hands with soap or disinfection with hand sanitizer containing minimum 60\% alcohol (if soap and 
water are not available); avoidance of contact with infected people and maintaining an appropriate distance as much as conceivable; and refraining from touching nose, eyes, and mouth with unwashed hands (CDC, 2019). World Health Organization issued complete guidelines on the use of face masks in the community, during care at home, and in the health care settings of COVID19. Health care personnel are recommended to use particulate respirators such as certified N95 or FFP2 during aerosol generating procedures and to use medical masks while providing any care to suspected or confirmed cases. In addition to handle the COVID-19 outbreak, the guideline also suggests to eliminate panic among the general population (www.nhc.gov.cn).

\section{Conclusion}

The occurrence of several coronaviruses caused a large variety of human and veterinary diseases in last few decades. The viruses will continue to emerge and evolve both in human as well as animal outbreaks due to their ability to recombine, mutate,

\section{REFERENCES}

CDC, 2020. 2019 novel coronavirus, Wuhan, China, 2020. https://www.cdc.gov/coronavirus/2019nCoV/summary.html. Accessed 1 Feb 2020

Chen N, Zhou M, Dong X, Qu J, Gong F et al., 2020. Epidemiological and clinical characteristics of 99 cases of 2019 novel coronavirus pneumonia in Wuhan, China: A descriptive study. Lancet, 395(10223): 507-513

Corman VM, Landt O, Kaiser M, Molenkamp R, Meijer A et al., 2020. Detection of 2019 novel coronavirus (2019-nCoV) by real-time RT-PCR. Euro Surveill, 25(3) pii: 2000045

Donnelly CA, Malik MR, Elkholy A, Cauchemez S, Van Kerkhove MD et al., 2019. Worldwide reduction in MERS cases and deaths since 2016. Emerg Infect Dis, 25(9): 1758-1760

Doyle LP and Hutchins LM, 1995. Transmissible gastroenteritis in pigs. J Am Vet Assoc, 108: 257

Drexler JF, Gloza-Rausch F, Glende J, Corman VM, Muth D et al., 2010. Genomic characterization of severe acute respiratory syndrome-related and infect multiple species. On the basis of the origination history of the other coronaviruses, SARS-CoV-2 is likely to be originated from bats and reported from Wuhan, China through an unknown intermediate host. Till date, no effective treatment or prevention policies are offered to be used against COVID-19. This pandemic outbreak has challenged the economic, medical and public health infrastructure all over the world. Time alone will decide how this novel virus will influence our lives in future. Moreover, the experience gathered from this COVID-19 episode will definitely compel the planners throughout the globe to be prepared for the worst consequences posed by other similar pathogens of zoonotic origin.

Conflict of interest: The authors of this manuscript declare that there is no conflict of interest.

\section{ACKNOWLEDGEMENT}

The authors express their sincere gratitude to the Hon'ble Vice Chancellor, West Bengal University of Animal and Fishery Sciences.

coronavirus in European bats and classification of corona viruses based on partial RNAdependent RNA polymerase gene sequences. J Virol, 84(21): 11336-11349

Ferguson NM, Cummings DA, Cauchemez S, Fraser C, Riley S et al., 2005. Strategies for containing an emerging influenza pandemic in Southeast Asia. Nature, 437: 209-214

Force ADT, Ranieri VM, Rubenfeld GD, Thompson BT, Ferguson ND et al., 2012. Acute respiratory distress syndrome: the Berlin Definition. JAMA, 307(23): 2526-2533, Epub. 2012/07/17, doi: 10.1001/jama.2012.5669. PubMed PMID: 22797452

Guan WJ, Ni ZY, Hu Y, Liang WH, Ou CQ et al., 2020. Clinical characteristics of coronavirus disease 2019 in China. N Engl J Med, 382(18): 17081720. Epub 2020/02/29, doi: 10.1056/ NEJMoa2002032. PubMed PMID: 32109013

Guan Y, Zheng BJ, He YQ, Liu XL, Zhuang ZX et al., 2003. Isolation and characterization of viruses 
related to the SARS coronavirus from animals in southern China. Science, 302: 276-278

Hassan S, Sheikh FN, Jamal S, Ezeh JK and Aktar A, 2020. Coronavirus (COVID-19): A review of clinical features, diagnosis, and treatment. Cureus, 12(3): e7355. doi:10.7759/cureus.7355

Hemida MG, Perera RA, Wang P, Alhammadi MA, Siu LY et al., 2013. Middle East Respiratory Syndrome (MERS) coronavirus seroprevalence in domestic livestock in Saudi Arabia, 2010 to 2013. Euro Surveill, 18(50): 20659

Hoffmann M, Kleine WH, Krüger N, Müller M, Drosten C et al., 2020. The novel coronavirus 2019 (2019-nCoV) uses the SARS-coronavirus receptor ACE2 and the cellular protease TMPRSS2 for entry into target cells. bioRxiv, doi: $10.1101 / 2020.01 .31 .929042$

https://www.aphis.usda.gov/aphis/newsroom/news/ sa_by_date/sa-2020/ny-zoo-covid-19

https://www.avma.org/resources-tools/animal-healthand- welfare/covid-19/sars-cov-2-animalsincluding-pets

https://www.medrxiv.org/content/10.1101/2020. 03.12. 20034728v3

https://www. worldometers. info/coronavirus/?

Ji W, Wang W, Zhao X, Zai J and Li X, 2020. Homologous recombination within the spike glycoprotein of the newly identified coronavirus may boost cross-species transmission from snake to human. J med virol, 92: $433-440$

Khan S, Siddique R, Shereen MA, Ali A, Liu J et al., 2020. The emergence of a novel coronavirus (SARS-CoV-2), their biology and therapeutic options. J Clin Microbiol, 58(5) pii: JCM.00187-20. doi: 10.1128/JCM.00187-20

Khemani RG, Smith LS, Zimmerman JJ and Erickson S, 2015. Pediatric Acute Lung Injury Consensus Conference G. Pediatric acute respiratory distress syndrome: definition, incidence, and epidemiology: proceedings from the Pediatric Acute Lung Injury Consensus Conference. Pediatr Crit Care Med, 16(5 Suppl 1): S23-S40, Epub 2015/06/04, doi: 10.1097/PCC.00000 00000000432. PubMed PMID: 26035358
Kristian GA, Andrew R, Lipkin WI, Edward CH and Robert FG, 2020. The proximal origin of SARSCoV-2. Nature Medicine, 26: 450-452

Lai CC, Shih TP, Ko WC, Tang HJ and Hsueh PR, 2020. Severe acute respiratory syndrome coronavirus 2 (SARS-CoV-2) and coronavirus disease-2019 (COVID-19): the epidemic and the challenges. Int J Antimicrob Agents, 55(3): 105924

Liu Y, Gayle AA, Wilder-Smith A and Rocklov J, 2020. The reproductive number of COVID-19 is higher compared to SARS coronavirus. J Travel Med, 27(2): 1-4

Luis AD, Hayman DT, O'Shea TJ, Cryan PM, Gilbert AT et al., 2013. A comparison of bats and rodents as reservoirs of zoonotic viruses: are bats special?. Proc Biol Sci, 280: 1-9

Moratelli R and Calisher $\mathrm{CH}, 2015$. Bats and zoonotic viruses: can we confidently link bats with emerging deadly viruses?. Mem Inst Oswaldo Cruz Rio De Janeiro, 110(1): 1-22

National Health Commission of People's Republic of China. Guidelines for public protection against novel coronavirus infection. 2020. http:// www.nhc.gov.cn/jkj/s 7915/202001/ bc661e49b5bc487dba182f5c49ac 445b.shtml. Accessed 31 Jan 2020

Ong SW, Tan YK, Chia PY, Lee TH, Ng OT et al., 2020. Air, surface environmental, and personal protective equipment contamination by severe acute respiratory syndrome coronavirus 2 (SARS-CoV-2) from a symptomatic patient. JAMA, 323(16): 1610-1612

Pratelli A, Martella V, Decaro N, Tinelli A, Camero M et al., 2003. Genetic diversity of a canine coronavirus detected in pups with diarrhoea in Italy. J Virol Methods, 110(1): 9-17

Reusken CB, Ababneh M, Raj VS, Meyer B, Eljarah A et al., 2013. Middle East Respiratory Syndrome coronavirus (MERS-CoV) serology in major livestock species in an affected region in Jordan, June to September 2013. Euro Surveill, 18(50): 20662

Rhodes A, Evans LE, Alhazzani W, Levy MM, Antonelli M et al., 2017. Surviving sepsis campaign: International guidelines for management of sepsis and septic shock: 2016. Intensive Care Med, 43(3): 304-377, Epub 
2017/01/20, doi: 10.1007/s00134-017-4683-6

Richman DD, Whitley RJ and Hayden FG, 2016. Clinical Virology. $4^{\text {th }}$ edn., Washington: A SM Press

Riviello ED, Kiviri W, Twagirumugabe T, Mueller A, Banner-Goodspeed VM et al., 2016. Hospital incidence and outcomes of the acute respiratory distress syndrome using the Kigali modification of the Berlin Definition. Am J Respir Crit Care Med,193(1): 52-59, Epub 2015/09/10. doi: 10.1164/rccm.201503-0584OC

Sahin AR, Erdogan A, Mutlu AP, Dineri Y, Cakirci AY et al., 2020. Novel coronavirus (COVID-19) outbreak: A review of the current literature. Eura J Med Onch, 4(1): 1-7

Saif LJ, 2004. Animal coronaviruses: what can they teach us about the severe acute respiratory syndrome?. Rev Sci Technol, 23: 643-660

Sanower, Upadhyay AK, Iram A, Singh NK and Maansi, 2020. COVID-19: A threat to mankind. Int J Adv Res Biol Sci, 7(4): 126-130

Wan Y, Shang J, Graham R, Baric RS and Li F, 2020. Receptor Recognition by the Novel Coronavirus from Wuhan: an Analysis Based on Decade-Long Structural Studies of SARS Coronavirus. J Virol, doi:10.1128/JVI.00127-20

Wang C, Horby PW, Hayden FG and Gao GF, 2020. A novel coronavirus outbreak of global health concern. Lancet, doi:10.1016/ S01406736(20)30185-9

Wang D, Hu B, Hu C, Zhu F, Liu Xet al., 2020. Clinical characteristics of 138 hospitalized patients with 2019 novel coronavirus-infected pneumonia in Wuhan, China. JAMA, 323(14): 1406-1407, Epub 2020/02/08, doi: 10.1001/jama.2020.1585

Wang L, Wang Y, Ye D and Liu Q, 2020. Review of the 2019 novel coronavirus (SARS-CoV-2) based on current evidence. Int $\mathrm{J}$ Antimicrob Agents,55(6):105924, doi:10.1016/ j.ijantimicag. 2020.105948

Wang M, Cao R, Zhang L, Yang X, Liu J et al., 2020. Remdesivir and chloroquine effectively inhibit the recently emerged novel coronavirus (2019$\mathrm{nCoV}$ ) in vitro. Cell Res, 30(3): 269-271

Weiss SL, Peters MJ, Alhazzani W, Agus MSD, Flori HR et al., 2020. Surviving sepsis campaign international guidelines for the management of septic shock and sepsis-associated organ dysfunction in children. Crit Care Med, 21(2): e52-e106, Epub 2020/02/08, doi: 10.1097/PCC.0000000000002198. PubMed PMID: 32032273

WHO, 2020. Laboratory testing of 2019 novel coronavirus (2019-nCoV) in suspected human cases: interim guidance, available at 2 March 2020. No. WHO/COVID19/laboratory/2020.4. World Health Organization

Woo PC, Huang Y, Lau SK and Yuen KY, 2010. Coronavirus genomics and bioinformatics analysis. Viruses, 2: 1804-1820

Wood JL, Leach M, Waldman L, Macgregor H, Fooks AR et al., 2012. A framework for the study of zoonotic disease emergence and its drivers: Spillover of bat pathogens as a case study. Philos Trans R Soc Lond Ser B Biol Sci, 367: 2881-1892

Wu Z and McGoogan JM, 2020. Characteristics of and important lessons from the coronavirus disease 2019 (COVID-19) outbreak in China: summary of a report of $72 / 314$ cases from the Chinese Center for Disease Control and Prevention. JAMA, 323(13): 1239-1242

Xu X, Chen P, Wang J, Feng J, Zhou H et al., 2020. Evolution of the novel coronavirus from the ongoing Wuhan outbreak and modeling of its spike protein for risk of human transmission. Sci China Life Sci, doi:10.1007/s 11427-020-1637-5

Yin Y and Wunderink RG, 2018. MERS, SARS and other coronaviruses as causes of pneumonia. Respirology, 23: 130-137

Zhang C, Zheng W, Huang X, Bell EW, Zhou X et al., 2020. Protein structure and sequence re-analysis of 2019-nCoV genome does not indicate snakes as its intermediate host or the unique similarity between its spike protein insertions and HIV-1. J Proteome Res, 19(4): 1351-1360

Zhou P, Yang XL, Wang XG, Hu B, Zheng L et al., 2020. A pneumonia outbreak associated with a new coronavirus of probable bat origin. Nature, 579: $270-273$

Zhu N, Zhang D, Wang W, Li X, Yang B et al., 2020. A novel coronavirus from patients with pneumonia in China, 2019. N Eng J Med, 382: 727-733

Received - 16.05.2020, Accepted - 25.05.2020, Published - 01.06.2020 